\section{Physical closeness and negative feelings*}

\author{
JAMES M. DABBS, JR. \\ Georgia State University, Atlanta, Ga. 30303
}

In a 2 by 2 design, 56 pairs of Ss argued or talked in a room which was either large or very small. Proximity in the small room was expected to increase arousal, which in turn would intensify either hostile feelings associated with arguing or friendly feelings associated with talking. Instead, verbal reports and palmar sweat measures suggested an affinity between proximity and arguing. Arguing is congruent with negative feelings aroused by proximity, and arguing may also allow Ss to focus upon intellectual content and thereby "escape" from an unpleasant interpersonal situation.

Albert \& Dabbs (1970) report that persuasive impact decreases when a speaker moves closer to his listener, presumably because perceived pressure from the speaker arouses reactance (Brehm, 1966) in the listener. It seems likely, however, that under some conditions proximity might arouse positive feelings and thereby improve communication. Proximity leads to arousal, as indicated by increases in skin conductance (McBride, King, \& James, 1965) and by improved performance on simple tasks and impaired performance on complex tasks (Barefoot \& Kleck, 1970). But arousal is not necessarily associated with any particular kind of affect and should be able to increase feelings which are either positive or negative (Schachter, 1964).

The present experiment was set up to explore the effects of physical distance on communication. Each $\mathbf{S}$ in a 2 by 2 design argued with his partner or had a friendly conversation in a room which was either large or very small. Arousal associated with proximity was expected to amplify the overall dominant tone of the discussion in the small room, making the argument more argumentative and the friendly conversation more friendly. An alternative possibility was that the crowded small room might produce predominantly positive or negative feelings, making this setting better suited for friendly conversation or for argument.

\section{METHOD}

One hundred and twelve male Ss from an introductory psychology volunteer subject pool reported for the experiment in groups for four. E took each $S$ to a cubicle and left him with an instruction sheet explaining that he would soon have a discussion with another $S$. After 1.5 min $E$ returned, took a measure of palmar sweating (see below), and left $S$ with background material to read in

*This research was supported by U.S. Public Health Service Grant CH-00044. The author wishes to thank Danny Carter for running the $S$ s. preparation for the discussion. About 5 min later $E$ returned again, introduced $S$ to one of the other (randomly selected) Ss, and took the pair to another room for their discussion. Ss were seated, a second measure of sweating taken on each, and $E$ left with assurances that no one would listen to them for the next $20 \mathrm{~min}$. After $20 \mathrm{~min} \mathrm{E}$ returned, announced the session was over, and took a third set of sweat measures. Ss were taken back to their cubicles, where each completed a questionnaire. Ss were given debriefing sheets; their questions were answered, and they were released.

Distance was varfed by having the discussion take place in a small or large room. The small room was $3^{1 / 2} \times 5 \mathrm{ft}$, with Ss' chairs not more than $2 \mathrm{ft}$ apart. The large room was about $12 \times 23 \mathrm{ft}$, with Ss' chairs $6 \mathrm{ft}$ apart. A drapery partition formed one longer side of the small room, and a window with closed venetian blinds covered one longer side of the large room. Both rooms were attractively painted and carpeted but relatively bare, with a small table in the small room and some office furniture at the end away from where Ss were seated in the large room. An alternate procedure was considered in which distance would have been varied in the same room by placing the chairs close together or far apart, but it was felt that chairs very close together in a large room would seem more unnatural than chairs close together in a small room.

The discussion dealt with the trustworthiness of medical advice. Ss received background material to prepare them for argument or for friendly talk on this topic. In the argue condition Ss were given background material supporting opposite sides of the issue. One $S$ in each pair read two pages supporting the position that physicans are well informed, seldom make mistakes, have high ethical standards, and offer good advice, while the other $S$ read two pages supporting the position that physicans cannot keep up with their fields, make frequent mistakes, have questionable ethics, and often give poor advice. Each S was instructed to argue for his side and to come to some overall conclusion with his partner. In the talk condition each $S$ read the material supporting both sides of the issue. He was told to have a friendly conversation and to use the discussion as a means of getting to know his partner.

Palmar sweating was measured as described by Dabbs, Johnson, \& Leventhal (1968). Pores containing sweat are visible in a fingerprint taken with this procedure, and the number of sweat glands active at a given moment can be counted. Palmar sweating is highly correlated with skin conductance (Johnson, 1968; Johnson \& Landon, 1965) and appears to be part of the mechansim underlying GSR (Montague \& Coles, 1966). Increases in palmar sweating are associated with increases in feelings of arousal (Dabbs et al, 1968).

Most items on the questionnaire administered at the end of the experiment included 5- or 7-point Likert-type response scales. $S$ reported how well he got along with and communicated with his partner, how much he and his partner agreed, how much he avoided open disagreement, how much pressure he felt in the situation generally and how much pressure specifically from his partner, how well he liked his partner, and how similar he felt toward his partner. $S$ also indicated on a check-list the degree to which he had felt friendly, cautious, attentive, irritated, distracted, imposed upon, aroused, uneasy, and happy during the discussion. One open-ended question asked $\mathbf{S}$ to describe his feelings during the discussion, and another inquired about suspicions he might have had. On a measure of selective attention, $\mathrm{S}$ indicated the percentages of time he had spent thinking about (1) the discussion topic, (2) his partner's behavior and physical appearance, and (3) other things.

Scores for individual Ss were combined into mean scores for each pair of Ss on each dependent variable, and all analyses were performed using pair scores. Thus 112 Ss were treated as 56 pairs, 14 in each cell of the 2 by 2 design. The repeated measures of palmar sweating constituted a third (within-Ss) way of the design.

The main effects of room size and discussion content are shown in Table 1. As can be seen in this table, Ss in the small room said the room was smaller and they were seated closer together. They felt generally under more pressure and disagreed more with their partners in the small room, but at the same time they tended to avoid 
Table 1

Main Effects of Room Size and Discussion Content

\begin{tabular}{|c|c|c|c|c|}
\hline \multirow[b]{2}{*}{ Questionnaire Item } & \multicolumn{2}{|c|}{ Room Size } & \multicolumn{2}{|c|}{$\begin{array}{c}\begin{array}{c}\text { Discussion } \\
\text { Content }\end{array} \\
\end{array}$} \\
\hline & Small & Large & Argue & Talk \\
\hline 1. How large was room? & 1.2 & 5.4 & - & - \\
\hline 2. Seated how far apart? & 1.4 & 4.6 & - & - \\
\hline 3. Felt generally under pressure? & 3.0 & 2.1 & 2.9 & 2.2 \\
\hline 4. Felt under pressure from partner? & 3.3* & $2.7^{*}$ & 3.2 & 1.6 \\
\hline 5. Reacted against pressure from partner? & - & - & 3.8 & 2.2 \\
\hline 6. Disagreed with partner? & 3.3 & 2.6 & 4.2 & 1.8 \\
\hline 7. Reached overall agreement? & - & - & 4.5 & 5.7 \\
\hline 8. Avoided open disagreement? & 2.4 & 1.8 & - & - \\
\hline \multicolumn{5}{|l|}{ 9. Checklist items: } \\
\hline Friendly? & 4.1* & $4.3^{*}$ & 4.0 & 4.3 \\
\hline Irritated? & 1.4* & $1.2^{*}$ & 1.4 & 1.2 \\
\hline Imposid upon? & - & - & 1.8 & 1.5 \\
\hline
\end{tabular}

*Differences between means marked "*" are significant at $p<.10$. Other differences between small and large rooms or between argue and talk are significant at $p<.05$. Means not printed where $p>.10$.

open disagreement. There were marginally significant tendencies for Ss to feel more pressure from their partners, to feel less friendly, and to feel more irritated in the small room. A picture emerges of generally more negative feelings in the small room, with some possible inhibition or suppression of these feelings.

Ss disagreed more and reached less overall agreement when arguing than when talking. They felt generally under more pressure and specifically under more pressure from their partners, and they reported reacting more against pressure from their partners. They felt less friendly, more irritated, and more imposed upon when arguing than when talking. The picture is one of disagreement and generally more negative feelings when arguing. (While feelings of friendliness were affected by both manipulations, liking for the partner showed no effect.)

There was also an interaction between distance and discussion. Table 2 shows the extent to which $\mathrm{Ss}$ reported paying attention to the discussion topic, as opposed to their partner's appearance or other things. Ss attended to the topic less when talking than when arguing $(F=23.33$, $\mathrm{df}=1 / 52, \mathrm{p}<.01$ ), less in the small than in the large room $(F=5.55$, $\mathrm{df}=1 / 52, \mathrm{p}<.05)$, and especially less when talking in the small room $[\mathrm{F}($ interaction $)=6.51, \mathrm{df}=1 / 52$, $p<.05]$. To describe the interaction differently, Ss attended to the topic

Table 2

Mean Percentage of Time Ss Reported Thinking About the Topic

\begin{tabular}{lcc} 
& \multicolumn{2}{c}{ Room Size } \\
\cline { 2 - 3 } $\begin{array}{l}\text { Discussion } \\
\text { Content }\end{array}$ & Small & Large \\
\hline Argue & $68 \%$ & $68 \%$ \\
Talk & $31 \%$ & $56 \%$ \\
\hline
\end{tabular}

equally well in the two rooms when arguing, but when talking they were less attentive in the small room.

The main effects of room size and discussion content also suggest an interaction, in that there seemed to be an affinity between room size and discussion content. Proximity aroused negative feelings, which might well provide a more suitable background for arguing than for talking.

Mean palmar sweat scores are shown in Fig. 1. The only significant effect in the overall analysis was a change in sweating over time $(\mathrm{F}=35.12$, df $=2 / 104, p<.01)$ in all conditions. But it can be seen that sweating decreased most when Ss argued in the small room, and an additional post hoc analysis was performed to examine this trend. Each pair of Ss was assigned a score representing the decrease in sweating from the first measure (the beginning of the experiment) to the mean of the second and third measures (the discussion session itself). A one-way analysis of variance of these change scores, forming a contrast between small-room/argue and the other three conditions, showed significantly more decrease in sweating in the small-room/argue condition $(\mathrm{F}=4.58, \mathrm{df}=1 / 52, \mathrm{p}<.05)$.

\section{DISCUSSION}

The Ss felt pressured, disagreeable, and unfriendly in the small room, feelings which are more appropriate conversation. Proximity did not produce content-free arousal which could be channeled to intensify either argument or friendly conversation.

Arguing was appropriate in the small room because it capitalized upon the negative feelings produced there. Arguing may also have been appropriate because it provided Ss with "escape" from an unpleasant situation. Ss paid more attention to for arguing than for friendly their partners' appearance and behavior in the small room. The partner seemed to be more distracting when he was close, and only when arguing did Ss stick to the topic about as well in the small room as in the large one. Perhaps argument provided an organized structure of intellectual content upon which Ss could focus, to avoid the difficulties of informal social exchange at an "unnaturally" close distance. Parenthetically, it should be noted that tasks other than arguing might provide similar escape. For example, the small room might facilitate cooperative problem solving, since Ss could focus on the problem and thereby avoid attending to their uncomfortably close partners.

In support of a withdrawal hypothesis, it may be recalled that there was less "agreement" but also less "open disagreement" in the small room. Open disagreement is often avoided in small groups (Argyris, 1969), a situation which can lead to there being more private disagreement than group members realize. The present data would suggest that such hidden disagreement is greater when groups meet under more crowded conditions.

The large decreases in palmar sweating in the small-room/argue condition can also be interpreted as reflecting withdrawal. Stotland (1969) states that "palmar drying" has no psychological significance, but it clearly can have significance if it reflects a drop in sweating to some less-than-average level. A problem with the present data is that there are no comparison measures to determine a $S$ 's baseline or "average" level of sweating. Some decrease in sweating could reflect regression from the initially high state of arousal associated with beginning the

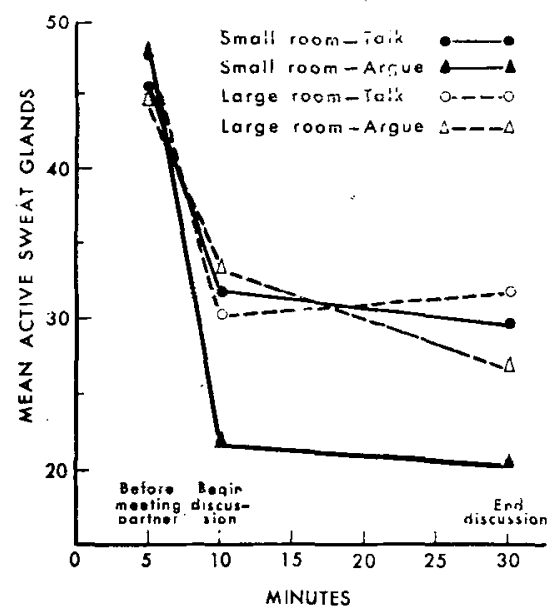

Fig. 1. Palmar sweating in the four experimental conditions. 
experiment, but mean sweating in the small-room/argue condition dropped to exceptionally low levels, levels lower than those reported by Johnson (1968), Dabbs et al, (1968), or Martens (1969). Dabbs et al (1968) argue that sweating will decrease when Ss' attention is directed away from the environment and toward inner concerns (i.e., when they withdraw).

It might seem inconsistent to conclude that withdrawal is conducive to argument, since argument requires an active confrontation between individuals. But there are no measures to indicate that argument was intensified (e.g., that it was louder) in the small room, and it may not have been particularly "arousing." Certainly it is possible for an intellectual argument to be less arousing than an exchange of personal feelings.

In summary, the effects of proximity were largely negative, as in the study by Albert \& Dabbs (1970). The nearness of another person did not increase overall arousal or facilitate communication. Ss were dissatisfied with proximity, tended to withdraw from interaction with their partners, and responded well to an argument upon which they could focus their attention.

\section{REFERENCES}

ALBERT, S., \& DABBS, J. M., JR. Physical distance and persuasion. Journal of Personality \& Social Psychology, 1970, 15, 265-270.

ARGYRIS, c. The incompleteness of social-psychological theory: Examples from small group, cognitive consistency, and attribution research. American Psychologist, 1969, 24, 893-908.

BAREFOOT, J. C., \& KLECK, R. E. The effects of race and physical proximity of a co-actor on the social facilitation of dominant responses. Mimeo, 1970.

BREHM, J. W. A theory of psychological reactance. New York: Academic Press, 1966.

DABBS, J. M., JR, JOHNSON, J, E, \& LEVENTHAL, H. Palmar sweating: A quick and simple measure. Journal of Experimental Psychology, 1968, 78 347-350.

JOHNSON, J. E. Measurement of the surgical patient's welfare. USPHS final progress report, 1968 .

JOHNSON, J. E., DABBS, J. M., JR., \& LEVENTHAL, H. Psychosocial factors in the welfare of surgical patients. Nursing Research, 1970, 19, 18-29.

JOHNSON, L. C., \& LANDON, M. M. Eccrine sweat gland activity and racial differences in resting skin conductance. Psychophysiology, 1965, 1, 322-327.

MARTENS, R. Palmax sweating and the presence of an audience. Journal of Experimental Social Psychology, 1969, 5, 371-374.

McBRIDE, G., KING, M. G., \& JAMES, J. W. Social proximity effects on galvanic skin responses in adult humans. Journal of Psychology, 1965, 61, 153-157.
MONTAGUE, J. D., \& COLES, E. M. Mechanism and measurement of the galvanic skin response. Psychological Bulletin 1966, 65, 261-279.

SCHACHTER, $S$. The interaction of cognitive and physiological determinants of emotional state. In L. Berk owitz (Ed.)
Advances in experimental social psychology, Vol. 1. New York: Academic Press, 1964.

STOTLAND, E. Exploratory investigations of empathy. In L. Berkowitz (Ed.), Aduances in experimental social psychology, Vol. 4. New York: Academic Press, 1969.

\title{
Preference for high variability in young children*
}

\author{
ANNE H. STEVENSON and DAVID B. LYNN \\ Department of Applied Behavioral Sciences \\ University of California, Davis, Calif. 95616
}

Eighty-eight children from 41 to 84 months of age were presented with random shapes containing $5,10,20$, and 40 independent turns in a paired-comparison design experiment. The raw data (i.e. preferences) were transformed into scale scores for the different levels of variability for each child. Analyses of variance showed: (1) a linear increase in preference with increasing variability, (2) a linear increase in preference for variability in increasing age, and (3) that boys had a slightly higher preference for variability than did girls.

In infants, preference for variability increases with age (Brennan, Ames, \& Moore, 1966; Munsinger \& Weir, 1967), while adults prefer stimuli of intermediate variability (Munsinger \& Kessen, 1964). Studies of variability preferences in young children have produced inconsistent results. Thomas (1966) found an increasing preference for variability in Ss from 6 years of age to midadolescence. However, Munsinger, Kessen, \& Kessen (1964) found a decreasing preference for variability in Ss 6 years and older, while Kaess \& Weir (1968) found no difference in stated preference for diverse levels of variability in Ss 29-66 months of age.

Young children (31/2-7 years of age) were used in the present study in an attempt to clarify the level of variability preferred by this age group. METHOD

There were $88 \mathrm{Ss}, 44$ of each sex, ranging in age from 41 to 84 months. There were four boys and four girls in each 4-month age interval. The

*This investigation was supported in part by University Patent Fund Research Grant DG 108. The authors are deeply indebted to Neal A. Kroll for statistica consultation. children were brought voluntarily by a parent to the testing session.

Pairs of random shapes (Munsinger \& Kessen, 1964) were back-projected onto a $4 \times 4 \mathrm{ft}$ translucent screen. The projected stimuli were $12 \times 12 \mathrm{in}$. and 4 in. apart. There were three examples of each of the four stimulus levels $(5$, 10,20 , and 40 turns), paired in all combinations of stimulus complexity and left-right position. When one figure was paired with a figure of a different stimulus level, both were removed from the exemplar pool and were not available for pairing with other stimuli The resulting 12 pairs were shown in the same random order during four presentations for a total of 48 presentations per testing session.

The testing was held in a small college classroom. The child was seated about 20 in. from the center of the screen. The $S$ was told to look at the stimuli and choose the one he liked best in each pair. The E observed the S's eye movements through a $2 \times 5$ in. one-way glass in the screen to be certain the $S$ was attending to the stimuli.

The 48 separate preference scores for each $\mathrm{S}$ were transformed into scale values of preference for each level of variability, using the method of least squares for paired comparisons 